\title{
Effects of maslinic acid on the proliferation and apoptosis of A549 lung cancer cells
}

\author{
XUE BAI, YI ZHANG, HONGFANG JIANG, PENG YANG, HUI LI, YUE ZHANG and PING HE \\ Department of Geriatrics, Shengjing Hospital of China Medical University, Shenyang, Liaoning 110004, P.R. China
}

Received December 3, 2014; Accepted October 27, 2015

DOI: $10.3892 / \mathrm{mmr} .2015 .4552$

\begin{abstract}
Maslinic acid (MA) is a pentacyclic triterpene acid that is present in numerous dietary plants. Although certain studies have demonstrated that MA has anti-cancer properties in different cell types, the effect of MA on lung cancer cell proliferation and apoptosis and the potential underlying mechanisms remain to be elucidated. In the present study, A549 lung cancer cells were treated with different doses of MA and it was found that MA significantly inhibited A549 cell growth in a dose-dependent manner. In addition, Annexin V/propidium iodide flow cytometric analysis demonstrated that MA induced apoptosis of A549 cells. The present study also confirmed that MA induced apoptosis by observing morphological alterations. In addition, the effect of MA treatment on the levels of apoptosis-associated proteins was examined. The results demonstrated that MA treatment suppressed the expression of caspase-3,-8 and -9, and increased the expression of cleaved caspase- $3,-8$ and -9 in a dose-dependent manner. The level of inhibitors of apoptosis (IAPs) and Smac, which are possible upstream factors of caspase proteins, were also examined. It was found that MA treatment increased the protein expression of Smac and decreased the protein levels of c-IAP1, c-IAP2, X-linked inhibitor of apoptosis protein (XIAP) and Survivin in a dose-dependent manner. These results suggested that MA inhibited proliferation and induced apoptosis of A549 cells through regulation of caspase cleavage as well as Smac, c-IAP1, c-IAP2, XIAP and Survivin.
\end{abstract}

\section{Introduction}

Lung cancer is the leading cause of cancer-associated mortality in the world (1) and non-small cell lung cancer (NSCLC) composes the majority of all lung carcinomas (2). Despite previous advances in diagnosis and treatment, the 5-year

Correspondence to: Dr Ping He, Department of Geriatrics, Shengjing Hospital of China Medical University, 36 Sanhao Road, Shenyang, Liaoning 110004, P.R. China

E-mail: hepingcmu@126.com

Key words: maslinic acid, apoptosis, caspase, inhibitors of apoptosis, Smac survival rate has remained $<15 \%$, with only a $5-10 \%$ survival rate for advanced NSCLC $(3,4)$. Therefore, identifying new therapeutic targets and agents to improve the prognosis of NSCLC is urgently required.

There has been a growing interest in the use of natural compounds as a new source of anti-tumor agent owing to their wide range of biological activities, low toxicity and weak side effects. Studies investigating the anti-tumor mechanisms of traditional Chinese herbal medicine, which are predominantly extracted from natural plants and animals, provide a theoretical basis and new strategies for the treatment of cancer. Currently, several anti-tumor components isolated from Chinese herbal medicines, including cephalotaxine, paclitaxel, podophyllotoxin, 10-hydroxycamptothecin and vinblastine, are used in clinical practice. Increasing attention has been paid to uncovering the anti-tumor potential and mechanisms of Chinese herbal medicine. Chinese herbs have been found to inhibit cell proliferation, angiogenesis and tumor metastasis, induce cell apoptosis and differentiation and regulate tumor-associated signaling pathways and the immune system (5-7), thus exhibiting anti-tumor potential in vitro and in vivo.

Maslinic acid (MA), a pentacyclic triterpene acid, is widely present in dietary plants and is particularly abundant in olive fruit skins. This compound has attracted significant interest due to its pharmacological safety and its various biological activities, including its anti-inflammatory, anti-bacterial, anti-viral and anti-oxidative properties (8-10). It has previously been reported that MA exerts anti-tumor effects on HT29 colon cancer cells, DU145 human prostate cancer cells and a mouse melanoma cell line, which were at least partially associated with apoptotic induction (11-13).

However, the effects of MA on various types of lung cancer remain to be elucidated. Thus, in the present study, the effects of MA on the proliferation and apoptosis of A549 lung cancer cells and the possible underlying mechanisms were examined.

\section{Materials and methods}

Reagents. MA was purchased from Shanghai Pure One Biotechnology Co., Ltd. (Shanghai, China). The extract used was a white powder comprising $98 \%$ MA and $2 \%$ oleanolic acid. This extract was stable when stored at $4^{\circ} \mathrm{C}$. It was dissolved prior to its use at $10 \mathrm{mg} / \mathrm{ml}$ in dimethyl sulfoxide (DMSO; Sigma-Aldrich, St. Louis, MO, USA). A stock solution was frozen and stored at $-20^{\circ} \mathrm{C}$. 
Cell culture. The A549 lung cancer cell line was obtained from the Department of Cell Biology (China Medical University, Shenyang, China) and cultured in RPMI-1640 (Gibco-BRL, Carlsbad, CA, USA) containing 10\% fetal calf serum (Beijing Solarbio Science \& Technology Co., Ltd., Beijing, China) at $37^{\circ} \mathrm{C}$ in $5 \% \mathrm{CO}_{2}$. The medium was changed daily and the cells were digested using $0.25 \%$ trypsin (Biological Industries, Beit HaEmek, Israel). Cells were treated with different doses of MA $(0,9,12,15,18$ and $21 \mu \mathrm{g} / \mathrm{ml})$ in their logarithmic growth phase.

MTT assay. A549 cells (1 $10^{5} /$ well) were plated in 96-well plates and cultured overnight. Subsequently, cells were incubated with different concentrations of MA $(0,9,12,15$, 18 and $21 \mu \mathrm{g} / \mathrm{ml}$ ) for $24 \mathrm{~h}$, respectively. The corresponding culture medium was used as an empty control. Briefly, $20 \mu \mathrm{l}$ of $5 \mathrm{mg} / \mathrm{ml}$ 3-(4,5-dimethylthiazol-2-yl)-2,5-diphenyltetrazolium bromide (MTT; Nanjing KeyGen Biotech. Co., Ltd., Nanjing, China) solution was added to each well and incubated for $4 \mathrm{~h}$ at $37^{\circ} \mathrm{C}$. The supernatant was then removed from each well and DMSO $(150 \mu \mathrm{l})$ was added to dissolve the formazan crystals. Absorbance was measured at $570 \mathrm{~nm}$ with a microplate reader (ELx808; BioTek Instruments, Winooski, VT, USA). Each experiment was performed in triplicate. The following formula was used to calculate the inhibition ratio: Inhibition ratio $(\%)=(1-\mathrm{M} / \mathrm{C}) \times 100 \%$, where $\mathrm{M}$ is the absorbance of MA-treated cells and $\mathrm{C}$ is the absorbance of control cells.

Flow cytometry. A549 cells (5x10\%/well) were plated in 6-well plates and cultured overnight. Subsequently, cells were treated with different concentrations of MA $(0,9,12,15,18$ and $21 \mu \mathrm{g} / \mathrm{ml}$ ) for $24 \mathrm{~h}$ and were harvested by $0.25 \%$ trypsin. The corresponding culture medium was used as the empty control. For Annexin V/propidium iodide (PI) apoptosis analysis, the cells were resuspended in $500 \mu \mathrm{l}$ of binding buffer and adjusted to $1 \times 10^{6} / \mathrm{ml}$. Staining solution containing $5 \mu 1$ Annexin V/fluorescein isothiocyanate and $5 \mu$ l PI (Nanjing KeyGen Biotech. Co., Ltd.) was added to the cells and then incubated at $2-8^{\circ} \mathrm{C}$ for $15 \mathrm{~min}$ in the dark. Following this, the cells were analyzed using a FACSCalibur flow cytometer (Becton Dickinson, Franklin Lakes, NJ, USA). CellQuest version 5.1 software (BD Biosciences, San Jose, CA, USA) was used to analyze the data. Each experiment was performed in triplicate.

Immunofluorescence. A549 cells (5x105/well) were seeded on slides in 6-well plates and cultured overnight. Subsequently, the cells were treated with $18 \mu \mathrm{g} / \mathrm{ml} \mathrm{MA}$ at $37^{\circ} \mathrm{C}$ and $5 \% \mathrm{CO}_{2}$ for $24 \mathrm{~h}$. Corresponding culture medium was used as the empty control. Cells were washed twice with cold phosphate-buffered saline (PBS), fixed with methanol and glacial acetic acid (3:1) for $15 \mathrm{~min}$, stained with Hoechst $33342(5 \mathrm{mg} / \mathrm{l})$ at $37^{\circ} \mathrm{C}$ for 15 min (Sigma-Aldrich), and mounted with $1 \%$ glycerol. Morphological alterations were observed using fluorescence microscopy (BX53; Olympus, Tokyo, Japan). Each experiment was performed in triplicate.

Western blot analysis. Cells were seeded in culture flasks, allowed to attach overnight and incubated with 12 or $18 \mu \mathrm{g} / \mathrm{ml}$ MA for $24 \mathrm{~h}$. An equal quantity of RPMI-1640 was added

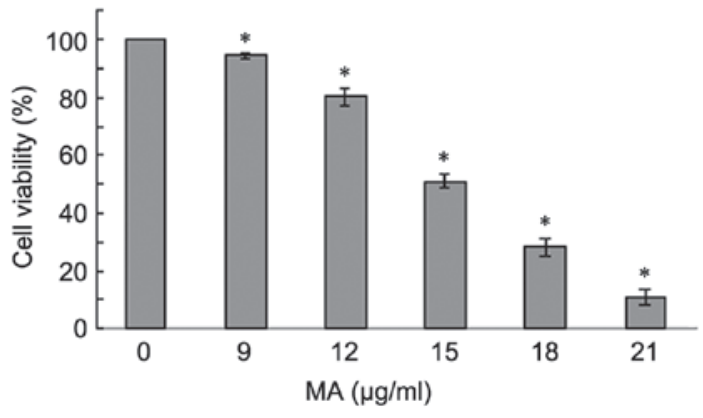

Figure 1. MA treatment inhibits the proliferation of A549 lung cancer cells. A549 cells were treated with different doses of MA $(0,9,12,15,18$ and $21 \mu \mathrm{g} / \mathrm{ml}$ ) for $24 \mathrm{~h}$. MTT assay demonstrated that the cell growth rate significantly decreased as the treatment dose increased. Columns show the mean value of three duplicates; bars represent standard deviation. ${ }^{*} \mathrm{P}<0.05$, compared with the $0 \mu \mathrm{g} / \mathrm{ml}$ MA group. MA, maslinic acid.

as a control. Following that, cells were harvested (cell number $>5 \times 10^{6} / \mathrm{ml}$ ) and washed twice with cold PBS. Western blot analysis was then performed. Briefly, the cell pellets were resuspended in lysis buffer (Nanjing KeyGen Biotech. Co., Ltd.) at $4^{\circ} \mathrm{C}$ for $1 \mathrm{~h}$. Following centrifugation at 12,000 x g for $20 \mathrm{~min}$, the supernatant was collected and stored at $-80^{\circ} \mathrm{C}$. The protein was quantified using a bicinchoninic acid quantification kit (Beyotime Institute of Biotechnology, Haimen, China). A total of $50 \mu \mathrm{g}$ of protein was separated by 10\% SDS-PAGE (Beijing Solarbio Science \& Technology Co., Ltd.) and transferred onto polyvinylidene fluoride membranes (Millipore, Billerica, MA, USA). The membranes were blocked with 5\% non-fat milk and incubated overnight at $4^{\circ} \mathrm{C}$ with the following antibodies: Mouse monoclonal anti-caspase-3 (1:200; cat. no. sc-7272), mouse monoclonal anti-caspase-8 (1:500; cat. no. sc-81656), mouse monoclonal anti-caspase-9 (1:1,000; cat. no. sc-73548), rabbit polyclonal anti-cleaved caspase-3 (1:500; cat. no. sc-22171), rabbit polyclonal anti-cleaved caspase- 8 (1:500; cat. no. sc-7890), goat polyclonal anti-cleaved caspase-9 (1:500; cat. no. sc-22182), mouse monoclonal anti-X-linked inhibitor of apoptosis protein (XIAP; 1:500; cat. no. sc-55552), mouse monoclonal anti-c-IAP1 (1:500; cat. no. sc-271419), rabbit polyclonal anti-c-IAP2 (1:500; cat. no. sc-7944), rabbit polyclonal anti-Survivin (1:500; cat. no. sc-10811), rabbit polyclonal anti-Smac (1:500; cat. no. sc-22766) and rabbit polyclonal anti-GAPDH (1:2,000; cat. no. sc-25778), all purchased from Santa Cruz Biotechnology, Inc. (Dallas, TX, USA). Following incubation with peroxidase-conjugated anti-goat IgG (1:3,000; cat. no. SC-2020; Santa Cruz Biotechnology, Inc.) and peroxidase-conjugated anti-rabbit IgG (1:3,000; cat. no. SC-2004; Santa Cruz Biotechnology, Inc.) at room temperature for $2 \mathrm{~h}$, proteins were visualized using enhanced chemiluminescence (Pierce Biotechnology, Inc., Rockford, IL, USA) and detected using BioImaging Systems (UVP Inc., Upland, CA, USA).

Statistical analysis. All data were analyzed with SPSS 13.0 software (SPSS, Inc., Chicago, IL, USA). All values are expressed as the mean \pm standard deviation. One-way analysis of variance and Fisher's least significant difference test was used to compare the differences between individual groups. $\mathrm{P}<0.05$ was considered to indicate a statistically significant difference. 

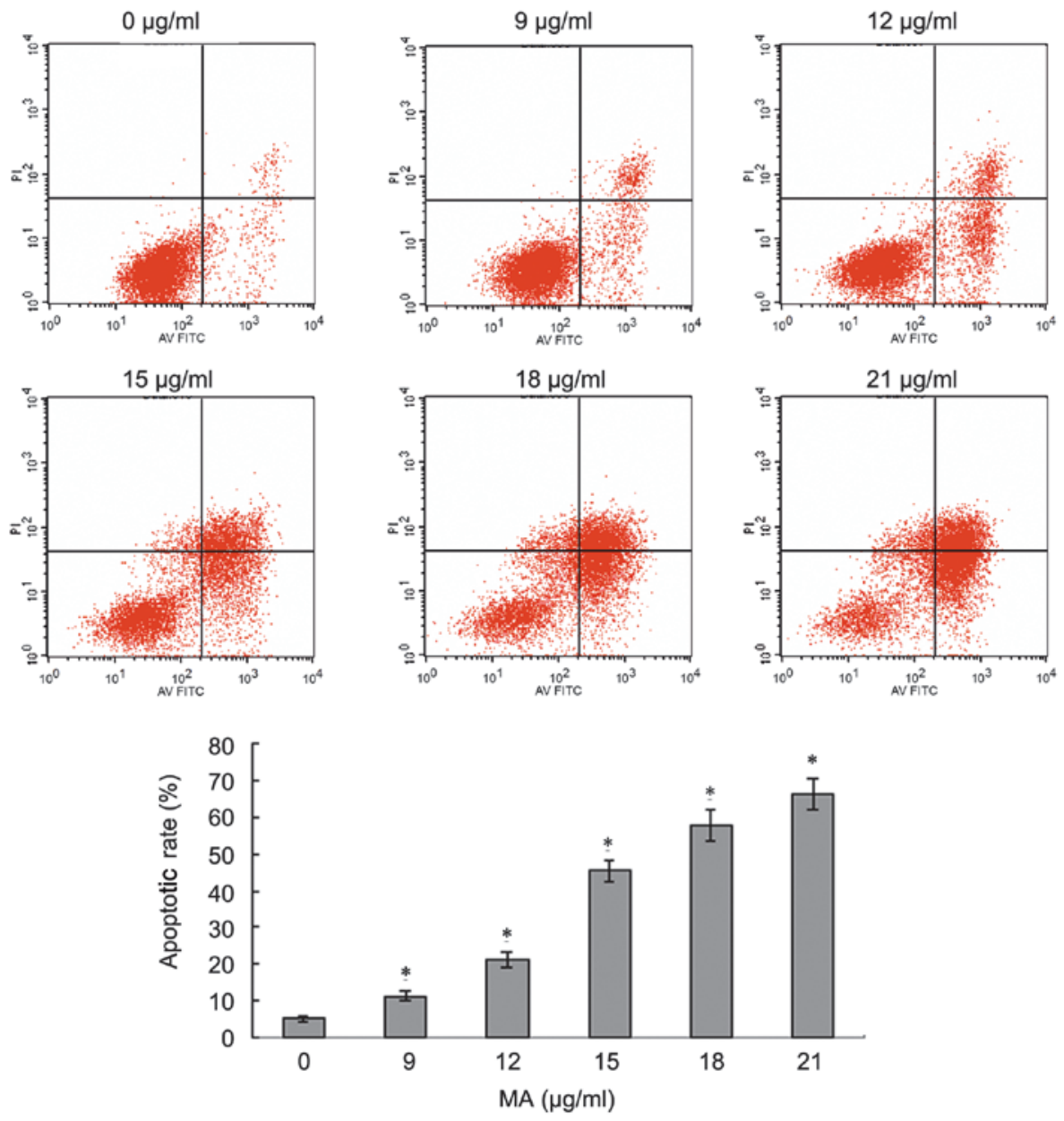

Figure 2. MA treatment induces apoptosis of A549 lung cancer cells. A549 cells were treated with different doses of MA $(0,9,12,15,18 \mathrm{and} 21 \mu \mathrm{g} / \mathrm{ml})$ for $24 \mathrm{~h}$. Annexin V/propidium iodide flow cytometric analysis demonstrated that the apoptotic rates induced by MA were significantly higher compared with that in untreated cells of the control group. When the dose of MA increased, more apoptotic cells were observed. Columns show the mean value of three duplicates; bars represent standard deviation. ${ }^{*} \mathrm{P}<0.05$, compared with the $0 \mu \mathrm{g} / \mathrm{ml}$ MA group. MA, maslinic acid.

\section{Results}

MA treatment inhibits the proliferation of A549 lung cancer cells. To examine the effect of MA on the proliferation of A549 cells, an MTT assay was performed in cells treated with different doses of MA $(0,9,12,15,18$ and $21 \mu \mathrm{g} / \mathrm{ml})$ for $24 \mathrm{~h}$. As the treatment dose increased, cell growth rate significantly decreased $(\mathrm{P}<0.05$; Fig. 1), suggesting that MA treatment suppressed A549 cell proliferation in a dose-dependent manner.

MA treatment induces apoptosis of A549 lung cancer cells. MA was reported to have anti-tumor effects on HT29 colon cancer cells, DU145 human prostate cancer cells and B16F0 mouse melanoma cell line, due to its role in apoptosis induction (12-14). Therefore, the effect of MA on the apoptosis of A549 cells was examined. A549 cells were incubated with different doses of MA $(0,9,12,15,18$ and $21 \mu \mathrm{g} / \mathrm{ml})$ for $24 \mathrm{~h}$ and then Annexin V/PI flow cytometric analysis was performed to investigate the effect of MA on the apoptosis of NSCLC cells. As shown in Fig. 2, early apoptosis and late apoptosis markedly increased as the concentration of MA increased. The percentages of apoptotic cells were 5.73, 11.31, 21.06, 44.72, 57.71 and $66.10 \%$ following treatment with $0,9,12,15,18$ and $21 \mu \mathrm{g} / \mathrm{ml}$ MA, respectively. The apoptotic rates induced by different doses of MA were significantly higher compared with that in untreated cells of the control group $(\mathrm{P}<0.05)$. When the dose of MA increased, the number of apoptotic cells increased. The results indicated that MA induced apoptosis of A549 cells in a dose-dependent manner.

MA treatment induces apoptotic morphological alterations in A549 lung cancer cells. Morphological alterations of cells is another important index of apoptotic detection. A549 cells were treated with $18 \mu \mathrm{g} / \mathrm{ml}$ MA for $24 \mathrm{~h}$, stained with Hoechst 33342 and were then observed under fluorescence microscopy. It was found that MA treatment caused marked morphological alterations, including chromatin condensation, karyopyknosis and nuclear fragmentation, which are characteristic features of apoptotic cells (Fig. 3). In accordance with flow cytometric analysis, when the dose of MA increased, more apparent morphological alterations and more apoptotic cells were observed.

MA treatment regulates the expression of apoptosis-associated proteins. To further examine the mechanism of MA-induced apoptosis, the effects of MA on the protein expression of caspase- $3,-8$ and -9 and cleaved caspase-3, -8 and -9 , which are important apoptosis-associated proteins, 


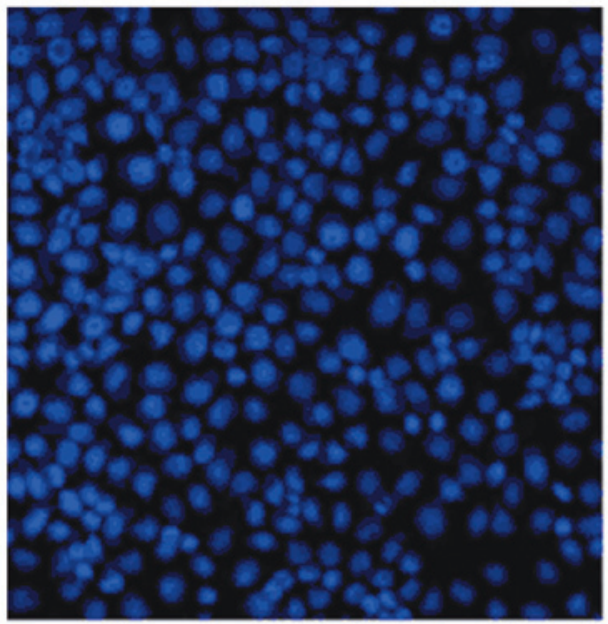

$0 \mu \mathrm{g} / \mathrm{ml}$

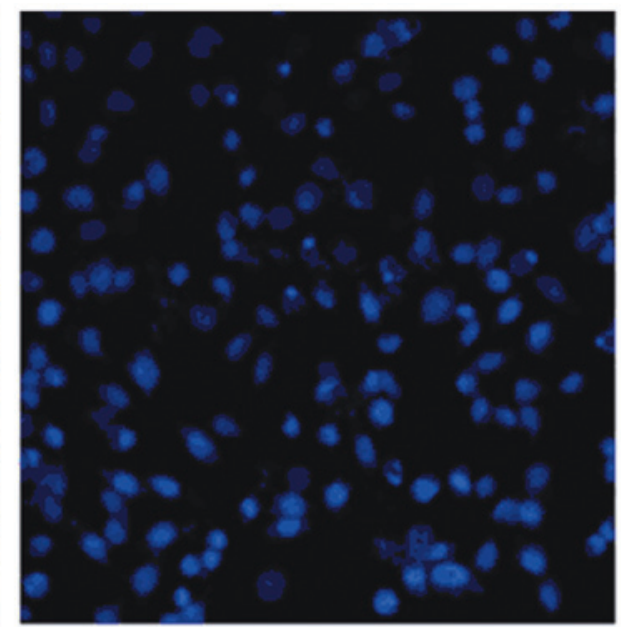

$18 \mu \mathrm{g} / \mathrm{ml}$

Figure 3. MA treatment induces apoptotic morphological alterations in A549 lung cancer cells. A549 cells were treated with 0 or $18 \mu \mathrm{g} / \mathrm{ml} \mathrm{MA} \mathrm{for} 24 \mathrm{~h}$ and stained with Hoechst 33342. Using fluorescence microscopy, it was found that MA treatment caused marked morphological alterations with apoptotic features. MA, maslinic acid.

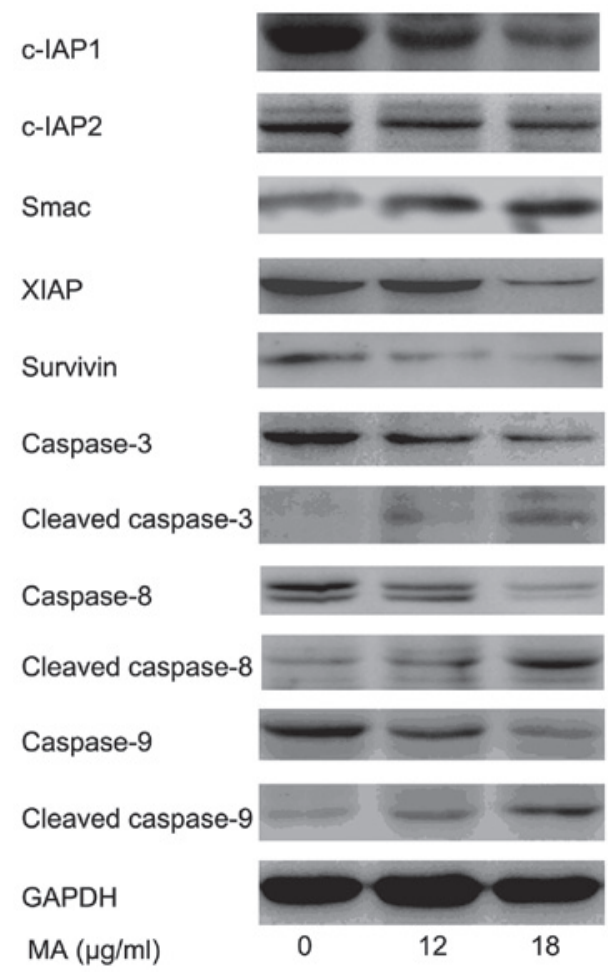

Figure 4. MA treatment regulates the expression of apoptosis-associated proteins. A549 cells were treated with different doses of MA $(0,12$ and $18 \mu \mathrm{g} / \mathrm{ml}$ ) for $24 \mathrm{~h}$. MA treatment increased the protein levels of Smac, cleaved caspase-3, -8 and -9 , and decreased the protein levels of c-IAP1, c-IAP2, XIAP, Survivin and caspase-3, -8 and -9 in a dose-dependent manner. MA, maslinic acid; XIAP, X-linked inhibitor of apoptosis protein; IAP, inhibitor of apoptosis

were examined. A549 cells were treated with either 12 or $18 \mu \mathrm{g} / \mathrm{ml} \mathrm{MA}$ for $24 \mathrm{~h}$ and then the levels of caspase family proteins were analyzed by western blot analysis. As shown in Fig. 4, MA treatment suppressed the expression of caspase-3, -8 and -9 , but promoted the expression of cleaved caspase- 3 , -8 and -9 . In addition, as the doses increased, caspase $-3,-8$ and -9 decreased and cleaved caspase- $3,-8$ and -9 increased, suggesting that MA regulated the cleavage of caspase- $3,-8$ and -9 in a dose-dependent manner.

Smac and inhibitors of apoptosis (IAPs) family proteins also have a critical role in the regulation of apoptosis by inhibiting caspase family proteins. Thus, the expression of Smac and IAP family proteins, including c-IAP1, c-IAP2, XIAP and Survivin was investigated in cells treated with different concentrations of MA $(0,12$ and $18 \mu \mathrm{g} / \mathrm{ml})$. MA treatment increased the protein level of Smac and decreased the protein levels of c-IAP1, c-IAP2, XIAP and Survivin in a dose-dependent manner (Fig. 4).

\section{Discussion}

Apoptosis is an active form of cellular suicide encoded by an endogenous program that can be triggered by either internal or external cues. It is well established that resistance to apoptosis is a hallmark of cancer (15) and suppression of apoptosis is closely associated with the progression of various types of cancer, including NSCLC.

Caspases are a family of cysteine-containing proteolytic enzymes that have a central role in the execution-phase of cell apoptosis. Currently, 14 mammalian caspases have been found, which exist as inactive proenzymes distributed in different cellular compartments. The caspases consist of two sub-groups, initiator caspases, including caspase-2, $-8,-9$ and -10 , and executioner caspases, including caspase- $3,-6$ and -7 , which form a caspase-cascade system that has a central role in the induction, transduction and amplification of intracellular apoptotic signals (16). Caspase-3 is a major caspase, which amplifies signals from intrinsic and extrinsic pathways (17). Caspase-8 is important in the death receptor-mediated extrinsic pathway. Caspase-9 is regarded as the canonical caspase in the intrinsic mitochondrial pathway that is regulated primarily by Bcl-2 family and Bcl-2 homologous domain-3 only proteins (18). Caspase- $-3,-8$ and -9 are synthesized as inactive pro-enzymes that are activated by proteolytic cleavage in cells undergoing apoptosis. 
In addition, IAP family proteins are important in the regulation of apoptosis by inhibiting caspases. This protein family includes XIAP, cellular IAP1/2 and Survivin. IAPs are often found to be overexpressed in several types of human cancer and contribute to chemoresistance $(19,20)$. XIAP can inhibit apoptosis by binding and inactivating caspases, including initiator caspase-9 and the effector caspase-3. XIAP is an important member of the mammalian IAP protein family, as it is the only member capable of inhibiting active caspases $(21,22)$. cIAP-1 and cIAP-2 are predominantly involved in the regulation of the extrinsic pathway of apoptosis, through the inhibition of caspase- 8 activation $(23,24)$. Survivin has been demonstrated to inhibit caspase-dependent apoptosis through co-operation with XIAP and interference with caspase-3/9 $(25,26)$. By contrast, Smac is a mitochondrial apoptogenic molecule that is released from the mitochondria in response to apoptotic stress. Smac is known to antagonize the function of IAPs (27-29).

Dysregulation of cell proliferation and apoptosis has been verified to be closely associated with tumor progression, and a number of anticancer drugs have been designed to induce apoptosis of cancer cells by targeting cellular processes, including cell growth, metabolism and proliferation (30). There has been a growing interest in the use of traditional Chinese medicines as a new source of anti-tumor agents owing to their wide range of biological activities, low toxicity and side effects. It is reported that certain terpenoids originating from Chinese medicine, particularly certain triterpenoids, have potential anti-tumor activities, which are often associated with apoptosis induction (31). MA is a pentacyclic triterpene acid, which is present in several dietary plants. This compound has been demonstrated to have abundant biological activities, including anti-inflammatory, anti-bacterial, anti-viral, anti-oxidative, anti-proliferative, anti-angiogeneic properties as well as the ability to induce apoptosis (32). Previous studies have demonstrated that MA has anti-cancer capacity in different cell types, including liver, breast, pancreatic and prostate cancer $(11,12,33-35)$. Specifically in colon malignancy, MA induced apoptosis in HT29 human colon cancer cells through the mitochondrial apoptotic pathway (35).

In the present study, the A549 lung cancer cell line was treated with different doses of MA and it was found that MA significantly inhibited A549 cell growth in a dose-dependent manner. In addition, AnnexinV/PI flow cytometric analysis was performed to investigate the effect of MA on the apoptosis of A549 cells. The results demonstrated that MA induced A549 apoptosis in a dose-dependent manner. Similarly, it was confirmed that MA induced apoptosis by observing the morphological alterations of cells, which exhibited typical apoptotic morphological characteristics. In addition, the effects of MA treatment on the protein expression of caspase-3, -8 and -9 and cleaved caspase-3, -8 and -9 , which are important apoptosis-associated proteins, were examined. As shown in the results, MA treatment suppressed the expression of caspase-3, -8 and -9 , but promoted the expression of cleaved caspase- $3,-8$ and -9 . As the dose increased, caspase-3, -8 and -9 decreased and cleaved caspase- $3,-8$ and -9 increased, suggesting that MA regulated caspase cleavage in a dose-dependent manner.

IAP family proteins are considered to regulate apoptosis by inhibiting caspases, while Smac is known to antagonize the function of IAPs. In order to examine the possible mechanism by which MA regulated the activity of caspase- $3,-8$ and -9 , the levels of IAPs and Smac, which are possible upstream regulators of caspases, were examined. The present study demonstrated that MA treatment increased the protein level of Smac and decreased the protein levels of c-IAP1, c-IAP2, XIAP and Survivin in a dose-dependent manner.

Taken together, the results indicated that MA treatment inhibited proliferation and induced apoptosis of A549 lung cancer cells. MA promoted apoptosis by regulating the cleavage of caspase- $3,-8$ and -9 in a dose-dependent manner. Furthermore, the results suggested that MA increases the expression of Smac and decreases the expression of c-IAP1, c-IAP2, XIAP and Survivin, which leads to caspase cleavage. MA treatment inhibited the proliferation of A549 lung cancer cells in a dose-dependent manner by inducing cell apoptosis. MA induced apoptosis via regulating the cleavage of caspase-3, -8 and -9 , by increasing Smac expression and decreasing c-IAP1, c-IAP2, XIAP and Survivin expression.

\section{Acknowledgements}

This study was supported by the Liaoning Province Science and Technology Plan project (grant no. 2013225021) and the Outstanding Scientific Fund of Shengjing Hospital (grant no. 201205).

\section{References}

1. Jemal A, Bray F, Center MM, Ferlay J, Ward E and Forman D: Global cancer statistics. CA Cancer J Clin 61: 69-90, 2011.

2. Raponi M, Zhang Y, Yu J, Chen G, Lee G, Taylor JM, Macdonald J, Thomas D, Moskaluk C, Wang Y and Beer DG: Gene expression signatures for predicting prognosis of squamous cell and adenocarcinomas of the lung. Cancer Res 66: 7466-7472, 2006.

3. Schiller JH, Harrington D, Belani CP, Langer C, Sandler A, Krook J, Zhu J and Johnson DH; Eastern Cooperative Oncology Group: Comparison of four chemotherapy regimens for advanced non-small-cell lung cancer. N Engl J Med 346: 92-98, 2002.

4. Mountain CF: The international system for staging lung cancer. Semin Surg Oncol 18: 106-115, 2000.

5. Hu B, Wang SS and Du Q: Traditional Chinese medicine for prevention and treatment of hepatocarcinoma: From bench to bedside. World J Hepatol 7: 1209-1232, 2015.

6. Huang CF, Lin SS, Liao PH, Young SC and Yang CC: The immunopharmaceutical effects and mechanisms of herb medicine. Cell Mol Immunol 5: 23-31, 2008.

7. Xu HB, Zheng LP, Li L, Xu LZ and Fu J: Elemene, one ingredient of a Chinese herb, against malignant tumors: A literature-based meta-analysis. Cancer Invest 31: 156-166, 2013.

8. Mokhtari K, Rufino-Palomares EE, Pérez-Jiménez A, Reyes-Zurita FJ, Figuera C, García-Salguero L, Medina PP, Peragón J and Lupiáñez JA: Maslinic acid, a triterpene from olive, affects the antioxidant and mitochondrial status of B16F10 melanoma cells grown under stressful conditions. Evid Based Complement Alternat Med 2015: 272457, 2012.

9. Yan SL, Yang HT, Lee HL and Yin MC: Protective effects of maslinic acid against alcohol-induced acute liver injury in mice. Food Chem Toxicol 74: 149-155, 2014.

10. Qin X, Qui C and Zhao L: Maslinic acid protects vascular smooth muscle cells from oxidative stress through Akt/Nrf2/HO-1 pathway. Mol Cell Biochem 390: 61-67, 2014

11. Reyes-Zurita FJ, Pachón-Peña G, Lizárraga D, Rufino-Palomares EE, Cascante M and Lupiáñez JA: The natural triterpene maslinic acid induces apoptosis in HT29 colon cancer cells by a JNK-p53-dependent mechanism. BMC cancer 11: 154, 2011.

12. Park SY, Nho CW, Kwon DY, Kang YH, Lee KW and Park JH: Maslinic acid inhibits the metastatic capacity of DU145 human prostate cancer cells: Possible mediation via hypoxia-inducible factor-1 $\alpha$ signalling. Br J Nutr 109: 210-222, 2013. 
13. Parra A, Rivas F, Martin-Fonseca S, Garcia-Granados A and Martinez A: Maslinic acid derivatives induce significant apoptosis in b16f10 murine melanoma cells. Eur J Med Chem 46: 5991-6001, 2011.

14. Peragón J, Rufino-Palomares EE, Muñoz-Espada I, Reyes-Zurita FJ and Lupiáñez JA: A new HPLC-MS method for measuring maslinic acid and oleanolic acid in HT29 and HepG2 human cancer cells. Int J Mol Sci 16: 21681-21694, 2015.

15. Hanahan D and Weinberg RA: Hallmarks of cancer: The next generation. Cell 144: 646-674, 2011.

16. Kuribayashi K, Mayes PA and El-Deiry WS: What are caspases 3 and 7 doing upstream of the mitochondria? Cancer Biol Ther 5: 763-765, 2006.

17. Lakhani SA, Masud A, Kuida K, Porter GA Jr, Booth CJ, Mehal WZ, Inayat I and Flavell RA: Caspases 3 and 7: Key mediators of mitochondrial events of apoptosis. Science 311: 847-851, 2006.

18. Fuentes-Prior P and Salvesen GS: The protein structures that shape caspase activity, specificity, activation and inhibition. Biochem J 384: 201-232, 2004

19. LaCasse EC, Baird S, Korneluk RG and MacKenzie AE: The inhibitors of apoptosis (IAPs) and their emerging role in cancer. Oncogene 17: 3247-3259, 1998.

20. Deveraux QL and Reed JC: IAP family proteins-suppressors of apoptosis. Genes Dev 13: 239-252, 1999.

21. Deveraux QL, Leo E, Stennicke HR, Welsh K, Salvesen GS and Reed JC: Cleavage of human inhibitor of apoptosis protein XIAP results in fragments with distinct specificities for caspases. EMBO J 18: 5242-5251, 1999.

22. Riedl SJ, Renatus M, Schwarzenbacher R, Zhou Q, Sun C, Fesik SW, Liddington RC and Salvesen GS: Structural basis for the inhibition of caspase-3 by XIAP. Cell 104: 791-800, 2001.

23. Rothe M, Pan MG, Henzel WJ, Ayres TM and Goeddel DV: The TNFR2-TRAF signaling complex contains two novel proteins related to baculoviral inhibitor of apoptosis proteins. Cell 83: $1243-1252,1995$.

24. Wang CY, Mayo MW, Korneluk RG, Goeddel DV and Baldwin AS Jr: NF-kappaB antiapoptosis: Induction of TRAF1 and TRAF2 and c-IAP1 and c-IAP2 to suppress caspase- 8 activation. Science 281: 1680-1683, 1998.
25. Li F: Survivin study: What is the next wave? J Cell Physiol 197: 8-29, 2003

26. Ambrosini G, Adida C and Altieri DC: A novel anti-apoptosis gene, survivin, expressed in cancer and lymphoma. Nat Med 3: 917-921, 1997.

27. Shiozaki EN and Shi Y: Caspases, IAPs and Smac/DIABLO Mechanisms from structural biology. Trends Biochem Sci 29 486-494, 2004

28. Srinivasula SM, Hegde R, Saleh A, Datta P, Shiozaki E, Chai J, Lee RA, Robbins PD, Fernandes-Alnemri T, Shi Y and Alnemri ES: A conserved XIAP-interaction motif in caspase-9 and Smac/DIABLO regulates caspase activity and apoptosis. Nature 410: 112-116, 2001

29. Song Z, Yao X and Wu M: Direct interaction between survivin and Smac/DIABLO is essential for the anti-apoptotic activity of survivin during taxol-induced apoptosis. J Biol Chem 278: 23130-23140, 2003.

30. Wang X, Feng Y, Wang N, Cheung F, Tan HY, Zhong S, Li C and Kobayashi S: Chinese medicines induce cell death: The molecular and cellular mechanisms for cancer therapy. Biomed Res Int 2014: 530342, 2014.

31. Leake I: Colorectal cancer: Chemopreventive action of synthetic triterpenoids in CRC. Nat Rev Gastroenterol Hepatol 11: 395 , 2014.

32. Yap WH and Lim YH: Mechanistic perspectives of maslinic acid in targeting inflammation. Biochem Res Int 2015: 279356 , 2015.

33. Lin CC, Huang CY, Mong MC, Chan CY and Yin MC: Antiangiogenic potential of three triterpenic acids in human liver cancer cells. J Agric Food Chem 59: 755-762, 2011.

34. Rufino-Palomares EE, Reyes-Zurita FJ, García-Salguero L, Mokhtari K, Medina PP, Lupiáñez JA and Peragón J: Maslinic acid, a triterpenic anti-tumoural agent, interferes with cytoskeleton protein expression in HT29 human colon-cancer cells. J Proteomics 83: 15-25, 2013.

35. Reyes-Zurita FJ, Rufino-Palomares EE, Lupiáñez JA and Cascante M: Maslinic acid, a natural triterpene from Olea europaea L., induces apoptosis in HT29 human colon-cancer cells via the mitochondrial apoptotic pathway. Cancer Lett 273: 44-54, 2009 